\title{
In vivo tau pathology is associated with synaptic loss and altered synaptic function
}

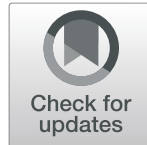

Emma M. Coomans ${ }^{1,2^{* \dagger}}$ (D), Deborah N. Schoonhoven ${ }^{2,3 \dagger}$, Hayel Tuncel ${ }^{1}$, Sander C. J. Verfaillie', Emma E. Wolters ${ }^{1,2}$, Ronald Boellaard', Rik Ossenkoppele 2,4, Anouk den Braber ${ }^{2}$, Wiep Scheper ${ }^{2,5,6}$, Patrick Schober ${ }^{7}$,

Steven P. Sweeney ${ }^{8}$, J. Michael Ryan ${ }^{8}$, Robert C. Schuit ${ }^{1}$, Albert D. Windhorst ${ }^{1}$, Frederik Barkhof ${ }^{1,9}$, Philip Scheltens $^{2}$, Sandeep S. V. Golla', Arjan Hillebrand ${ }^{3}$, Alida A. Gouw ${ }^{2,3}$ and Bart N. M. van Berckel ${ }^{1}$

\begin{abstract}
Background: The mechanism of synaptic loss in Alzheimer's disease is poorly understood and may be associated with tau pathology. In this combined positron emission tomography (PET) and magnetoencephalography (MEG) study, we aimed to investigate spatial associations between regional tau pathology ( $\left({ }^{18} \mathrm{~F}\right]$ flortaucipir PET), synaptic density (synaptic vesicle 2A [ $\left.{ }^{11} \mathrm{C}\right]$ UCB-J PET) and synaptic function (MEG) in Alzheimer's disease.

Methods: Seven amyloid-positive Alzheimer's disease subjects from the Amsterdam Dementia Cohort underwent dynamic 130-min [ $\left.{ }^{18} \mathrm{~F}\right]$ flortaucipir PET, dynamic 60-min $\left[{ }^{11} \mathrm{C}\right]$ UCB-J PET with arterial sampling and $2 \times 5$-min restingstate MEG measurement. $\left[{ }^{18} \mathrm{~F}\right]$ flortaucipir- and $\left[{ }^{11} \mathrm{C}\right] \cup C \mathrm{CB}-J$-specific binding (binding potential, BP ${ }_{\mathrm{ND}}$ ) and MEG spectral measures (relative delta, theta and alpha power; broadband power; and peak frequency) were assessed in cortical brain regions of interest. Associations between regional $\left[{ }^{18} \mathrm{~F}\right]$ flortaucipir $\mathrm{BP}_{\mathrm{ND}},\left[{ }^{11} \mathrm{C}\right] \cup C \mathrm{C}-J \mathrm{BP}_{\mathrm{ND}}$ and MEG spectral measures were assessed using Spearman correlations and generalized estimating equation models.

Results: Across subjects, higher regional $\left[{ }^{18} \mathrm{~F}\right]$ flortaucipir uptake was associated with lower $\left[{ }^{11} \mathrm{C}\right]$ UCB-J uptake. Within subjects, the association between $\left[{ }^{11} \mathrm{C}\right] \cup \mathrm{CB}-J$ and $\left[{ }^{18} \mathrm{~F}\right]$ flortaucipir depended on within-subject neocortical tau load; negative associations were observed when neocortical tau load was high, gradually changing into opposite patterns with decreasing neocortical tau burden. Both higher $\left[{ }^{18} \mathrm{~F}\right]$ flortaucipir and lower $\left[{ }^{11} \mathrm{C}\right]$ UCB-J uptake were associated with altered synaptic function, indicative of slowing of oscillatory activity, most pronounced in the occipital lobe.
\end{abstract}

Conclusions: These results indicate that in Alzheimer's disease, tau pathology is closely associated with reduced synaptic density and synaptic dysfunction.

Keywords: Alzheimer, Tau, Synaptic density, Synaptic function, PET, MEG

\footnotetext{
*Correspondence: e.coomans@amsterdamumc.nl

${ }^{\dagger}$ Emma M. Coomans and Deborah N. Schoonhoven contributed equally to this work.

'Department of Radiology \& Nuclear Medicine, Amsterdam Neuroscience,

Vrije Universiteit Amsterdam, Amsterdam UMC, Amsterdam, The Netherlands

${ }^{2}$ Alzheimer Center Amsterdam, Department of Neurology, Amsterdam

Neuroscience, Vrije Universiteit Amsterdam, Amsterdam UMC, Amsterdam,

The Netherlands

Full list of author information is available at the end of the article
}

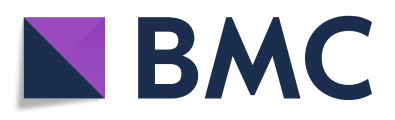

(- The Author(s). 2021 Open Access This article is licensed under a Creative Commons Attribution 4.0 International License, which permits use, sharing, adaptation, distribution and reproduction in any medium or format, as long as you give appropriate credit to the original author(s) and the source, provide a link to the Creative Commons licence, and indicate if changes were made. The images or other third party material in this article are included in the article's Creative Commons licence, unless indicated otherwise in a credit line to the material. If material is not included in the article's Creative Commons licence and your intended use is not permitted by statutory regulation or exceeds the permitted use, you will need to obtain permission directly from the copyright holder. To view a copy of this licence, visit http://creativecommons.org/licenses/by/4.0/. The Creative Commons Public Domain Dedication waiver (http://creativecommons.org/publicdomain/zero/1.0/) applies to the data made available in this article, unless otherwise stated in a credit line to the data. 


\section{Introduction}

Synaptic and neuronal loss, combined with $\beta$-amyloid (Aß) plaques and neurofibrillary tangles (NFT), comprise the main pathological characteristics of Alzheimer's disease (AD) [1]. Clinico-pathological studies have indicated synaptic loss as the major structural correlate of cognitive decline in $\mathrm{AD}[2,3]$. In patients with $\mathrm{AD}$, previous positron emission tomography (PET) studies have shown that the degree and spatial distribution of in vivo tau pathology closely correlates with disease severity, clinical symptoms and $\mathrm{AD}$ phenotypes [4-7]. This makes tau a likely candidate to be associated with synaptic loss in AD. Indeed, neuropathological evidence suggests that pathological tau isoforms localize at the synapse [8-12], where it can have devastating effects on synaptic structure and function [13, 14]. However, to date information describing the link between tau pathology and synaptic loss in the human brain is mainly limited to post-mortem studies.

The novel synaptic $\left[{ }^{11} \mathrm{C}\right] \mathrm{UCB}-\mathrm{J}$ PET radiotracer has nanomolar affinity for the presynaptic vesicle glycoprotein 2A (SV2A) [15], providing a direct in vivo measure of synaptic density [16]. Recent studies in patients with AD have observed strongest reductions in SV2A radiotracer-binding in the hippocampus [17-19], a key region for structural synaptic degeneration in AD [20]. Furthermore, a recent PET study observed an association between decreased SV2A-binding and increased tau-binding in the medial temporal lobe in patients with amnestic mild cognitive impairment [21].

While $\left[{ }^{11} \mathrm{C}\right] \mathrm{UCB}-\mathrm{J}$ PET is a measure of synaptic density, magnetoencephalography (MEG) provides a direct measure of synaptic activity as it measures the magnetic fields generated by post-synaptic currents, allowing measurement of synaptic (dys)function in vivo with high temporal resolution [22, 23]. Neuronal oscillatory activity is strongly linked to the balance between synaptic currents from inhibitory interneurons and excitatory pyramidal cells [24]. Typically, healthy neuronal circuits are in an equilibrium between synaptic excitation and inhibition [24], which is critical for the formation of oscillations [25]. Disturbances in this balance can disrupt oscillatory activity and thereby cause dysfunction. Interestingly, in a computational modelling study, alterations to the excitation-inhibition balance led to the onset of $\mathrm{AD}$ hallmarks such as oscillatory slowing and loss of absolute broadband power [26]. Measures of synaptic activity and function can be obtained using spectral MEG metrics such as relative power, absolute (broadband) power and peak frequency. Previous MEG studies in $\mathrm{AD}$ have described a global cortical slowing of neuronal oscillatory activity, as reflected by higher relative power in the lower (delta and theta) frequency bands, lower relative power in the higher (alpha and beta) frequency bands and lower peak frequency [27].
It is currently unknown how and to what extent tau pathology is associated with changes in synaptic density (structure) and activity (function) in patients with AD. In the present proof-of-concept study, we investigated the associations between tau pathology $\left(\left[{ }^{18} \mathrm{~F}\right]\right.$ flortaucipir PET), synaptic density $\left(\left[{ }^{11} \mathrm{C}\right] \mathrm{UCB}-\mathrm{J}\right.$ PET $)$ and oscillatory activity (MEG) in subjects with AD. We hypothesized that regional higher $\left[{ }^{18} \mathrm{~F}\right]$ flortaucipir uptake is associated with lower $\left[{ }^{11} \mathrm{C}\right] \mathrm{UCB}-\mathrm{J}$ uptake. In addition, we hypothesized that regional higher $\left[{ }^{18} \mathrm{~F}\right]$ flortaucipir uptake and lower $\left[{ }^{11} \mathrm{C}\right]$ UCB-J uptake are associated with lower absolute broadband power and measures that are indicative of slowing of oscillatory activity (i.e. higher relative delta and theta power, lower relative alpha power and lower peak frequency).

\section{Methods}

\section{Subjects}

Seven subjects with a clinical diagnosis of probable AD [28] were included from the Amsterdam Dementia Cohort after extensive clinical screening [29]. All subjects had positive biomarkers for $A ß$ pathology by means of cerebrospinal fluid (CSF) $A \beta_{1-42}$ and/or visual read of Aß-PET $\left(\left[{ }^{11} \mathrm{C}\right] \mathrm{PiB}, \quad\left[{ }^{18} \mathrm{~F}\right]\right.$ florbetaben, or $\left[{ }^{18} \mathrm{~F}\right]$ flutemetamol). Exclusion criteria were a Mini-Mental State Examination (MMSE) score of $<18$, magnetic resonance imaging (MRI) medial temporal atrophy score of $\geq 3$, blood haemoglobin levels $\leq 8$ for males and $\leq 7$ for females, presence of major psychiatric or neurological disorders other than $\mathrm{AD}$, severe claustrophobia and the presence of intracorporal devices interfering with MEG signals. The BEBO Foundation Medical Ethics Committee (Assen, The Netherlands) and the local Institutional Review Board of the VUmc (Amsterdam, The Netherlands) approved the study. All subjects provided written informed consent prior to the study.

\section{PET acquisition procedures}

All subjects underwent two 60-min dynamic $\left[{ }^{11} \mathrm{C}\right] \mathrm{UCB}-\mathrm{J}$ PET scans within \pm 28 days as they additionally took part in a kinetic modelling study to assess $\left[{ }^{11} \mathrm{C}\right] \mathrm{UCB}-\mathrm{J}$ testretest variability [30]. For each subject, the first $\left[{ }^{11}\right.$ C]UCB-J PET was used for data analysis. In addition, all subjects underwent a 130 -min dynamic $\left[{ }^{18} \mathrm{~F}\right]$ flortaucipir PET scan with a median time lag between $\left[{ }^{11} \mathrm{C}\right] \mathrm{UCB}-$ $\mathrm{J}$ and $\left[{ }^{18} \mathrm{~F}\right]$ flortaucipir PET of 95 days (interquartile range 133 days). All PET scans were acquired on an Ingenuity TF PET/CT scanner (Philips Medical Systems, Best, The Netherlands), preceded by a low-dose CT scan for attenuation correction purposes. $\left[{ }^{11} \mathrm{C}\right] \mathrm{UCB}-\mathrm{J}$ and $\left[{ }^{18} \mathrm{~F}\right]$ flortaucipir radiotracer syntheses were performed on-site $[15,31]$. Prior to PET scanning, all subjects received a venous cannula for tracer injection. For the $\left[{ }^{11} \mathrm{C}\right] \mathrm{UCB}-\mathrm{J}$ PET scan, an additional radial artery cannula for arterial 
sampling was inserted in order to obtain a metabolite corrected plasma input function for full quantification of $\left[{ }^{11} \mathrm{C}\right]$ UCB-J [30]. Dynamic 60-min $\left[{ }^{11} \mathrm{C}\right]$ UCB-J PET data were acquired immediately following a bolus injection of $329 \pm 31 \mathrm{MBq}\left[{ }^{11} \mathrm{C}\right] \mathrm{UCB}-J$. Each $\left[{ }^{11} \mathrm{C}\right] \mathrm{UCB}-J$ PET dataset consisted of 19 frames [30]. $\left[{ }^{18} \mathrm{~F}\right]$ flortaucipir PET data were acquired immediately following a bolus injection of $229 \pm 12 \mathrm{MBq}\left[{ }^{18} \mathrm{~F}\right]$ flortaucipir as described previously [31]. All PET data were 3D reconstructed using the vendor provided image reconstruction method (RAML A) with a matrix size of $128 \times 128 \times 90$ and a final voxel size of $2 \times 2 \times 2 \mathrm{~m}^{3}$. All standard corrections for attenuation, scatter, randoms, decay and dead time were performed.

\section{MRI acquisition procedures}

Three-dimensional T1-weighted MRI scans were acquired for all patients on a 3.0T Ingenuity TF PET/MR system (Philips Medical Systems, Best, The Netherlands) within a maximum of 2 and 6 months from $\left[{ }^{11} \mathrm{C}\right] \mathrm{UCB}-\mathrm{J}$ and $\left[{ }^{18} \mathrm{~F}\right]$ flortaucipir PET, respectively. None of the subjects had significant structural abnormalities that may have interfered with the analysis of the PET scans.

\section{MEG acquisition procedures}

Six out of seven subjects additionally underwent MEG measurement within 6 months from the $\left[{ }^{18} \mathrm{~F}\right]$ flortaucipir PET scan (median 125 days, interquartile range 84 days) and within 9 months from the $\left[{ }^{11} \mathrm{C}\right] \mathrm{UCB}-\mathrm{J}$ scan (median 170 days, interquartile range 217 days). MEG-data were acquired by means of a 306-channel whole-head MEGsystem (Elekta Neuromag Oy, Helsinki, Finland), while subjects were supine in a magnetically shielded room (VacuumSchmelze GmbH, Hanua, Germany). Two 5min eyes-closed resting-state recordings were acquired. Subjects were instructed to relax and stay awake. Several times during the recordings, subjects were instructed to briefly open their eyes. Magnetic fields were recorded with a sample frequency of $1250 \mathrm{~Hz}$, using an online anti-aliasing filter of $410 \mathrm{~Hz}$ and a high-pass filter of 0.1 $\mathrm{Hz}$. The subjects' head position in relation to the MEG sensors was continuously recorded using signals from five head-localization coils.

\section{PET and MEG imaging analyses}

Structural 3D T1-weighted MR images were coregistered to the PET images using Vinci software. For each subject, regions of interests (ROIs) were defined on the co-registered MRI scan with the Hammers template [32], which is incorporated in PVElab, a software programme that uses a probability map of 60 delineated (grey matter) ROIs that has been validated previously [33]. These ROIs were then superimposed onto the dynamic PET scans to extract regional time activity curves (TACs). $\left[{ }^{11} \mathrm{C}\right] \mathrm{UCB}-\mathrm{J}$ data were analysed using a plasma input reversible single tissue compartmental model with blood volume correction $\left(1 \mathrm{~T} 2 \mathrm{k}_{-} \mathrm{V}_{\mathrm{B}}\right)$ to fit the regional TACs, in order to obtain regional volumes of distribution $\left(\mathrm{V}_{\mathrm{T}}\right.$, the tissue-to-plasma concentration ratio at equilibrium) $[34,35]$. Binding potential $\left(\mathrm{BP}_{\mathrm{ND}}\right)$ was calculated for each ROI using a manually delineated centrum semi-ovale as reference region $\left(\mathrm{BP}_{\mathrm{ND}}=\mathrm{V}_{\mathrm{T}_{-} \mathrm{ROI}} /\right.$ $\left.\mathrm{V}_{\mathrm{T}_{-} \text {reference }}-1\right)$ [15, 17]. Centrum semi-ovale $\mathrm{V}_{\mathrm{T}}$ was used as the reference region for quantification of $\left[{ }^{11} \mathrm{C}\right] \mathrm{UCB}-\mathrm{J}$ $[15,30]$. In addition, only for visualization purposes, parametric SRTM2-derived $\mathrm{BP}_{\mathrm{ND}}$ images were generated. For $\left[{ }^{18} \mathrm{~F}\right]$ flortaucipir data, receptor parametric mapping (RPM)-derived $\mathrm{BP}_{\mathrm{ND}}$, with grey matter cerebellum as reference region, were obtained, which is a validated method to quantify tau load [36]. A partial volume correction method that combines Van Cittert iterative deconvolution methods (IDM) with highly constrained back projection (HYPR) was applied to the $\left[{ }^{18} \mathrm{~F}\right]$ flortaucipir $\mathrm{BP}_{\mathrm{ND}}$ data for a better quantification of the dynamic PET signal [37]. Partial volume correction was not applied to the $\left[{ }^{11} \mathrm{C}\right] \mathrm{UCB}-\mathrm{J}$ data, because there is currently no validated method available for that purpose.

The PET-co-registered MRI scan and the subjectspace Hammers template were additionally used in MEG analyses. Raw MEG-data were visually inspected for malfunctioning and noisy channels, which were subsequently removed, after which the temporal extension of Signal Space Separation (tSSS) in MaxFilter software (Elekta Neuromag Oy, version 2.2.12) [38] was applied in order to remove artefacts from the data [39]. Data were subsequently filtered in the $0.5-48 \mathrm{~Hz}$ band using MaxFilter software. Each subjects' MEG data were coregistered with the PET-coregistered MRI using surface matching, after which the same transformation was applied to the subject-space Hammers template. In order to reconstruct neuronal activity at source level, an atlasbased beamforming approach was applied [40], using the centroids [41] of the 67 parcels in the Hammers template. For each of these centroid voxels (i.e. virtual electrodes), time-series of neuronal activity were reconstructed by projecting the sensor signals to source space. Broadband data $(0.5-48 \mathrm{~Hz})$ were used for the estimation of the beamformer weights, in order to avoid overestimation of covariance between channels [42], as well as a unity noise covariance matrix, a spherical head model (fitted to the scalp surface as extracted from the MRI) and an equivalent current dipole as source model. On average $300 \mathrm{~s}$ of data (range 297-303 s) was used for the estimation of the data covariance matrix, which was regularized using singular value truncation with the default setting of 1e-06 times the maximum singular value. The optimum orientation of the equivalent current dipole was found using singular value decomposition [43]. 
The broadband sensor-level data were subsequently and sequentially projected through the normalized beamformer weights [44], resulting in a time-series for each voxel. The time-series for these voxels were subsequently used for further analysis. For each subject, 10 non-overlapping, artefact-free, eyes-closed, downsampled epochs of 4096 samples (13.1072 s) were selected, based on careful visual inspection. Inspection and further analysis was done using in-house software Brainwave (version 0.9.152.12.26, available from http:// home.kpn.nl/stam7883/brainwave.html). A discrete Fast Fourier transform was applied to the time series of each parcel $(n=67)$ in order to estimate absolute broadband $(0.5-48 \mathrm{~Hz})$ power, which is the sum of power across all bands; the relative power (power for a band divided by the sum of power for all bands) in three canonical MEG frequency bands (delta $(0.5-4 \mathrm{~Hz})$, theta $(4-8 \mathrm{~Hz})$ and alpha $(8-3 \mathrm{~Hz}))$; and the peak-frequency, defined here as the dominant frequency in the $4-13 \mathrm{~Hz}$ range $[26,27]$. Per subject, these spectral measures were averaged over epochs.

Mean $\left[{ }^{11} \mathrm{C}\right] \mathrm{UCB}-\mathrm{J}$ and $\left[{ }^{18} \mathrm{~F}\right]$ flortaucipir $\quad \mathrm{BP}_{\mathrm{ND}}$ were extracted within, and mean MEG spectral measures were used for 12 a priori selected bilateral cortical ROIs [45, 46] of the Hammers template, namely those in the temporal (middle and inferior temporal gyri; superior temporal gyrus, posterior temporal lobe), parietal (superior parietal gyrus, inferolateral parietal lobe), occipital (cuneus, lateral occipital lobe) and frontal (middle frontal gyrus, superior frontal gyrus, inferior frontal gyrus, orbitofrontal gyrus, gyrus rectus) lobes. To enable exploration of associations with cognition across subjects, we computed volume-weighted averages of $\left[{ }^{11} \mathrm{C}\right] \mathrm{UCB}-\mathrm{J} \mathrm{BP}_{\mathrm{ND}}$ and $\left[{ }^{18} \mathrm{~F}\right]$ flortaucipir $\mathrm{BP}_{\mathrm{ND}}$ and averages for MEG spectral measures across ROIs.

\section{Statistical analyses}

We performed two sets of analyses. Firstly, Spearman correlation models (IBM SPSS Statistics, version 26) were performed across ROIs and subjects, as well as across ROIs within subjects (separate analyses), to investigate associations between $\left[{ }^{18} \mathrm{~F}\right]$ flortaucipir $\mathrm{BP}_{\mathrm{ND}}$ and $\left[{ }^{11} \mathrm{C}\right] \mathrm{UCB}-\mathrm{J} \mathrm{BP}_{\mathrm{ND}}$. To compensate for inter-regional dependencies within each subject, significant associations were subsequently assessed using generalized estimating equation (GEE) with $\left[{ }^{18} \mathrm{~F}\right]$ flortaucipir $\mathrm{BP}_{\mathrm{ND}}$ as the predictor, $\left[{ }^{11} \mathrm{C}\right] \mathrm{UCB}-\mathrm{J} \mathrm{BP}_{\mathrm{ND}}$ as the outcome variable, and each subject as the repeated measure, using an exchangeable working correlation matrix and a robust estimator.

In a second set of analyses, associations between $\left[{ }^{18} \mathrm{~F}\right]$ flortaucipir $\mathrm{BP}_{\mathrm{ND}}$ or $\left[{ }^{11} \mathrm{C}\right] \mathrm{UCB}-\mathrm{J} \mathrm{BP}_{\mathrm{ND}}$ and MEG spectral measures were investigated across subjects. Analyses were performed separately for each brain lobe, as physiological brain oscillatory characteristics are region-dependent [27, 47]. For example, occipital regions are the main cortical generators of the dominant oscillatory activity in the alpha frequency range $(8-13 \mathrm{~Hz})$ during resting-state conditions [48], whereas alpha activity in frontal regions is low in general. Furthermore, the frontal regions in MEG have a lower signal-to-noise ratio. We therefore decided to stratify the analyses by brain lobes instead of performing one analysis encapsulating all brain lobes. Spearman correlations were performed across ROIs and subjects (for each brain lobe separately), and significant associations were subsequently assessed using GEE analyses (with $\left[{ }^{18} \mathrm{~F}\right]$ flortaucipir $\mathrm{BP}_{\mathrm{ND}}$ or $\left[{ }^{11} \mathrm{C}\right] \mathrm{UCB}-\mathrm{J} \mathrm{BP}_{\mathrm{ND}}$ as the predictor and MEG spectral measures as the outcome) to correct for possible inter-regional dependencies. A $p<0.05$ was considered statistically significant.

Finally, to explore whether each imaging modality was associated with cognition, we performed Spearman correlation analyses between MMSE and average $\left[{ }^{18} \mathrm{~F}\right]$ flortaucipir $\mathrm{BP}_{\mathrm{ND}}, \quad\left[{ }^{11} \mathrm{C}\right] \mathrm{UCB}-\mathrm{J} \mathrm{BP}_{\mathrm{ND}}$ and MEG spectral measures. We selected relative alpha power based on previous work [49]. Additionally, we added absolute broadband power as it contains all frequency bands. Because relative alpha power is most prominently observed in the occipital lobe [48], we used occipital relative alpha power and absolute broadband power for these analyses.

\section{Results}

Seven $\mathrm{A} \beta$-biomarker supported $\mathrm{AD}$ dementia subjects ( 3 female; 4 male) with a mean age of $64.3 \pm 8.2$ years and MMSE score of $24.1 \pm 1.8$ were included. Figure 1 presents the $\left[{ }^{18} \mathrm{~F}\right]$ flortaucipir PET and corresponding co-registered $\left[{ }^{11} \mathrm{C}\right] \mathrm{UCB}-J$ PET and MEG broadband power plot for each subject, with subjects ordered from high to low values of neocortical $\left[{ }^{18} \mathrm{~F}\right]$ flortaucipir $\mathrm{BP}_{\mathrm{ND}}$. Upon visual inspection, brain regions with high $\left[{ }^{18} \mathrm{~F}\right]$ flortaucipir $\mathrm{BP}_{\mathrm{ND}}$ corresponded closely with the regions that showed most prominent decreases in $\left[{ }^{11} \mathrm{C}\right] \mathrm{UCB}-\mathrm{J} \mathrm{BP}_{\mathrm{ND}}$, mainly observed in temporoparietal regions. Furthermore, low MEG broadband power was observed in temporal regions for all subjects.

\section{Associations between $\left[{ }^{18} \mathrm{~F}\right]$ flortaucipir $\mathrm{BP} \mathrm{ND}_{\mathrm{ND}}$ and $\left[{ }^{11} \mathrm{C}\right] \mathrm{UCB}$ - $J \mathrm{BP}_{\mathrm{ND}}$}

First, we examined the association between tau pathology and synaptic density. Across subjects and ROIs, higher $\left[{ }^{18} \mathrm{~F}\right]$ flortaucipir $\mathrm{BP}_{\mathrm{ND}}$ was associated with lower $\left[{ }^{11} \mathrm{C}\right]$ UCB-J $\mathrm{BP}_{\mathrm{ND}}(r=-0.47, p<0.001)$ (Fig. 2a, with $\mathrm{AD}$ subject numbers analogous to Fig. 1). This association remained significant after correcting for dependency of ROIs within subjects using GEE analyses $(\beta=-0.30, p<$ 0.001 ). Within each subject separately, in subjects with the highest neocortical tau levels, higher $\left[{ }^{18} \mathrm{~F}\right]$ flortaucipir $\mathrm{BP}_{\mathrm{ND}}$ was associated with lower $\left[{ }^{11} \mathrm{C}\right] \mathrm{UCB}-\mathrm{J} \mathrm{BP}_{\mathrm{ND}}$ across 
AD patient 2: 55-60y female, MMSE 22

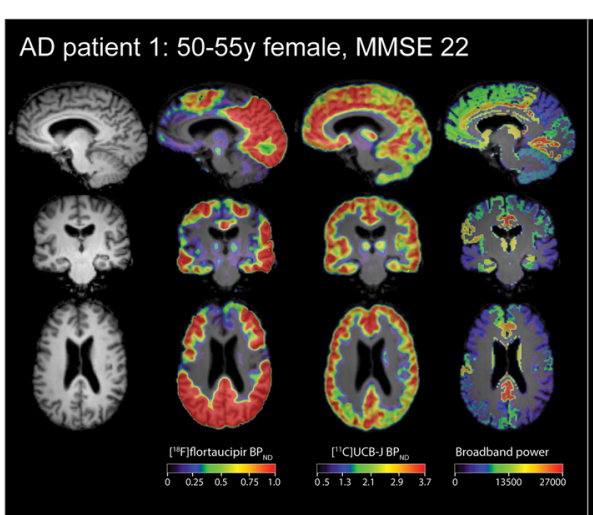

AD patient 3: 55-60y male, MMSE 24
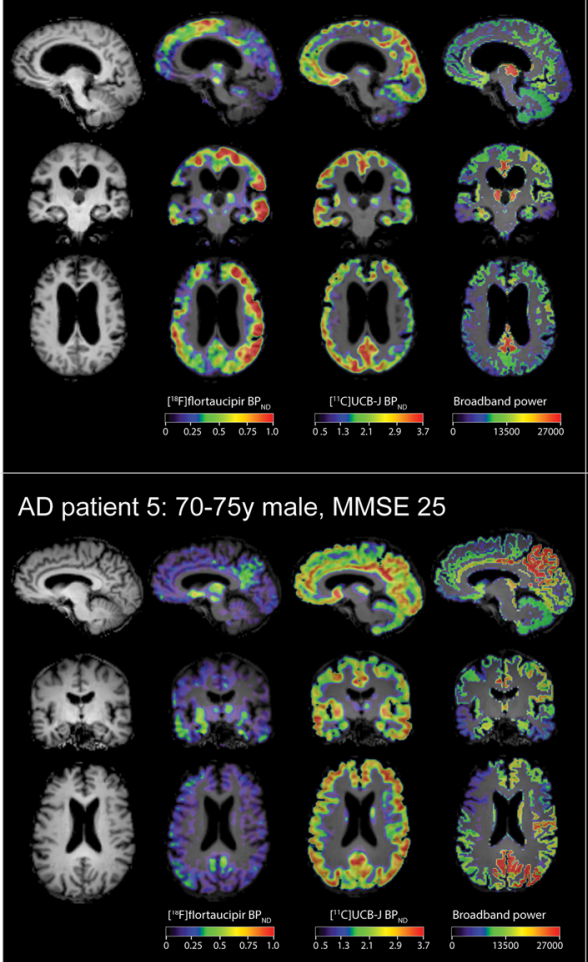
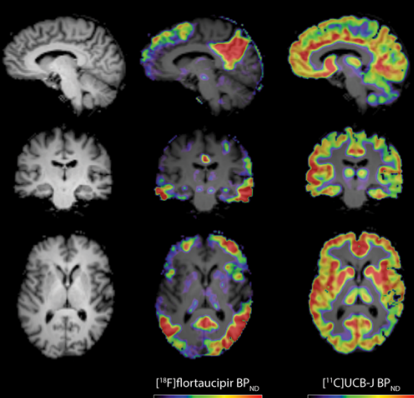

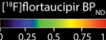

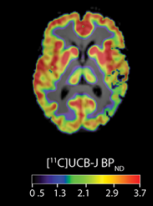

AD patient 4: 65-70y female, MMSE 24

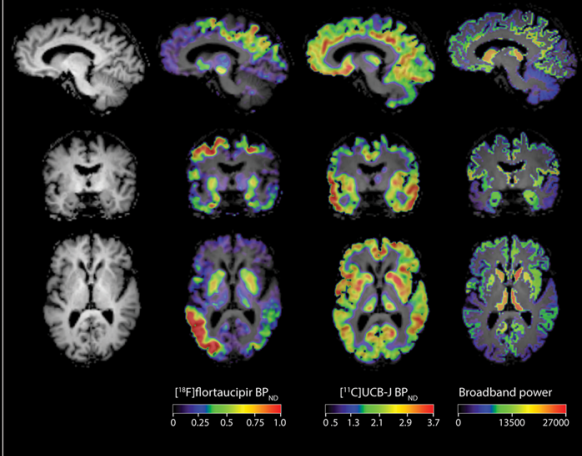

AD patient 6: 70-75y male, MMSE 25

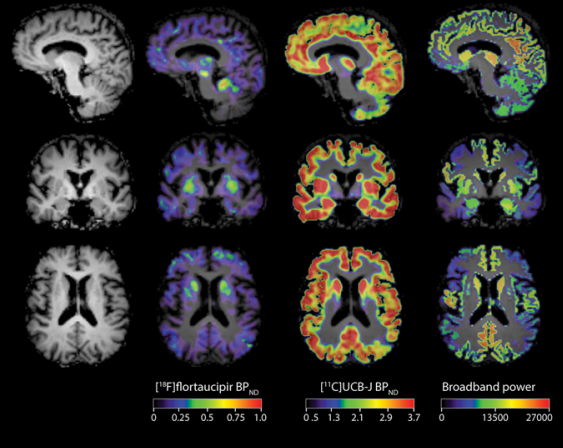

AD patient 7: 65-70y male, MMSE 27

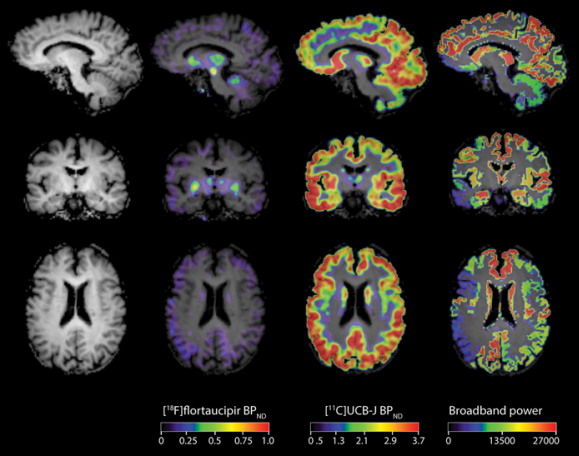

Fig. 1 Regional distributions of $\left[{ }^{18} \mathrm{~F}\right]$ flortaucipir $\mathrm{BP}_{\mathrm{ND}},\left[{ }^{11} \mathrm{C}\right] \cup \mathrm{CB}-J \mathrm{BP}_{\mathrm{ND}}$ and $\mathrm{MEG}$ absolute broadband power of each subject. Shown are parametric images of RPM-derived [ $\left.{ }^{18} \mathrm{~F}\right]$ flortaucipir $\mathrm{BP}_{\mathrm{ND}}$, parametric images of SRTM2-derived $\left[{ }^{11} \mathrm{C}\right] \mathrm{UCB}-J \mathrm{BP}_{\mathrm{ND}}$ and MEG broadband power in all ROls from the Hammers template. The order of patients corresponds to the order of average $\left[{ }^{18} \mathrm{~F}\right]$ flortaucipir BP ND (high to low) 


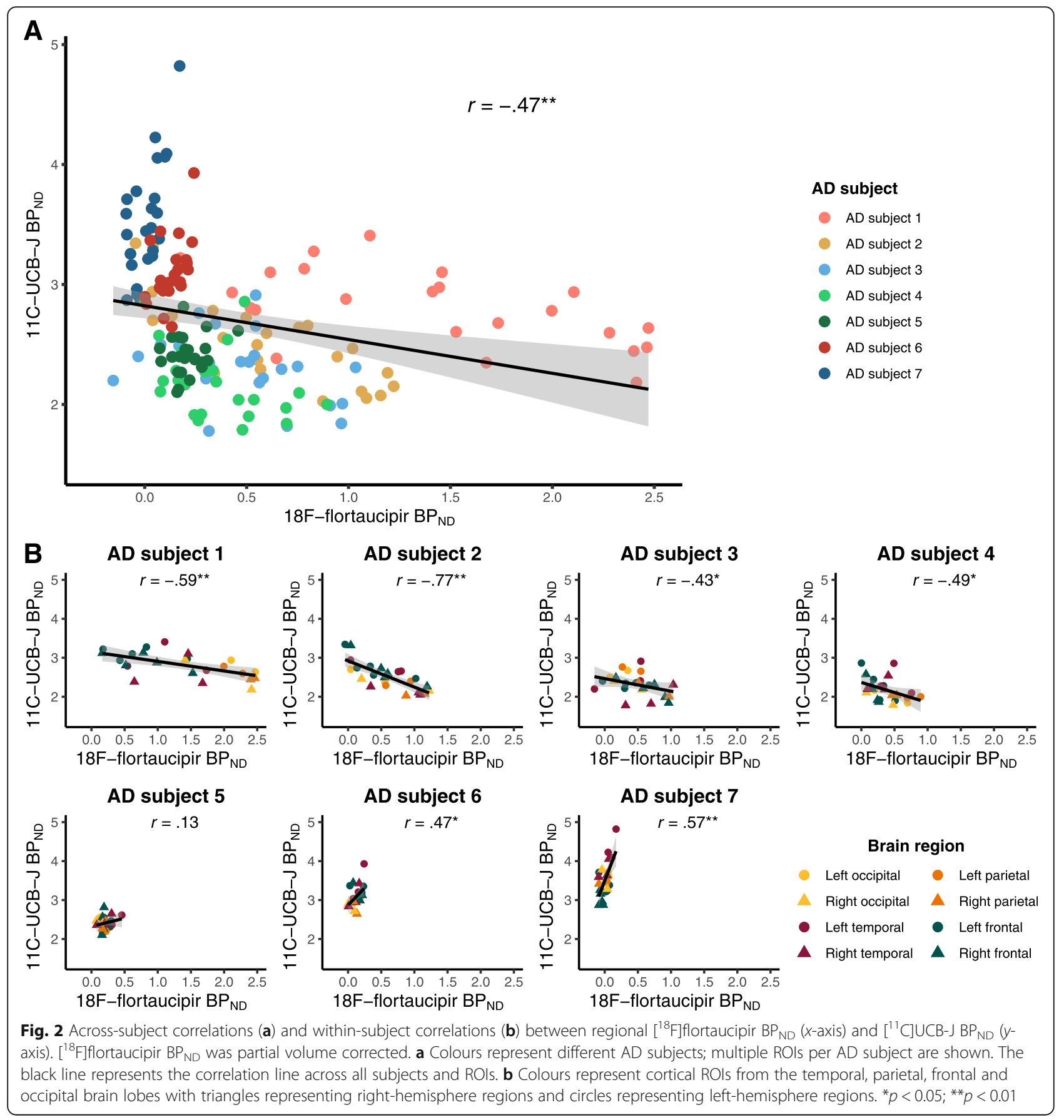

ROIs (AD subjects 1-4: $r=-0.59, p=0.003 ; r=-0.77$, $p<0.001 ; r=-0.43, p=0.04$; and $r=-0.49, p=0.02$, respectively) (Fig. 2b). In contrast, within subjects with relatively low neocortical tau levels, higher $\left[{ }^{18} \mathrm{~F}\right]$ flortaucipir $\mathrm{BP}_{\mathrm{ND}}$ was associated with higher $\left[{ }^{11} \mathrm{C}\right] \mathrm{UCB}-\mathrm{J} \mathrm{BP}_{\mathrm{ND}}$ across ROIs (AD subject 6-7: $r=0.47, p=0.02$, and $r=$ $0.57, p=0.004$, respectively) (Fig. 2b). Associations remained unchanged when using the second $\left[{ }^{11} \mathrm{C}\right] \mathrm{UCB}-\mathrm{J}$ PET scan instead of the first $\left[{ }^{11} \mathrm{C}\right] \mathrm{UCBJ}$ PET scan.
Associations between $\left[{ }^{18} \mathrm{~F}\right]$ flortaucipir $\mathrm{BP}_{\mathrm{ND}},\left[{ }^{11} \mathrm{C}\right] \mathrm{UCB}-\mathrm{J}$ $\mathrm{BP}_{\mathrm{ND}}$ and MEG spectral measures

Second, we examined the association between tau pathology and synaptic function. Table 1 shows all Spearman correlation coefficients. Higher regional $\left[{ }^{18} \mathrm{~F}\right]$ flortaucipir $\mathrm{BP}_{\mathrm{ND}}$ was associated with lower relative alpha power (occipital: $r=-0.60, p=0.002$; parietal: $r=-0.48 p=0.017$ ), lower relative theta power (occipital: $r=-0.54, p=0.007$ ) and higher relative delta power (occipital: $r=0.66, p=$ 
Table 1 Across-subject Spearman correlations between regional $\left[{ }^{18} \mathrm{~F}\right]$ flortaucipir $B P_{N D}$ or $\left[{ }^{11} \mathrm{C}\right] U C B-J$ BP ND and MEG power spectral measurements

\begin{tabular}{|c|c|c|c|c|}
\hline & \multicolumn{4}{|c|}{$\left[{ }^{18} \mathrm{~F}\right]$ flortaucipir $\mathrm{BP}_{\mathrm{ND}} \mathrm{Vs}$. MEG spectral measures } \\
\hline & Occipital & Temporal & Parietal & Frontal \\
\hline Relative delta power $(0.5-4 \mathrm{~Hz})$ & $0.66^{* *}$ & 0.27 & 0.24 & $-0.36^{* *}$ \\
\hline Relative theta power $(4-8 \mathrm{~Hz})$ & $-0.54^{* *}$ & -0.26 & -0.33 & 0.07 \\
\hline Relative alpha power $(8-13 \mathrm{~Hz})$ & $-0.60 * *$ & -0.25 & $-0.48^{*}$ & 0.08 \\
\hline Absolute broadband power $(0.5-48 \mathrm{~Hz})$ & $-0.74^{* *}$ & $-0.51 * *$ & $-0.54^{* *}$ & $-0.50 * *$ \\
\hline \multirow[t]{3}{*}{ Peak frequency } & -0.06 & -0.03 & 0.30 & -0.08 \\
\hline & \multicolumn{4}{|c|}{$\left[{ }^{11} \mathrm{C}\right] \mathrm{UCB}-\mathrm{J} \mathrm{BP}_{\mathrm{ND}}$ vs. MEG spectral measures } \\
\hline & Occipital & Temporal & Parietal & Frontal \\
\hline Relative delta power $(0.5-4 \mathrm{~Hz})$ & $-0.54^{* *}$ & 0.17 & 0.10 & $0.44^{* *}$ \\
\hline Relative theta power $(4-8 \mathrm{~Hz})$ & $0.73^{* *}$ & 0.25 & $0.52 * *$ & -0.05 \\
\hline Relative alpha power $(8-13 \mathrm{~Hz})$ & $0.52^{*}$ & -0.15 & 0.31 & -0.06 \\
\hline Absolute broadband power $(0.5-48 \mathrm{~Hz})$ & $0.50 *$ & -0.08 & -0.07 & -0.11 \\
\hline Peak frequency & 0.03 & -0.20 & -0.33 & -0.05 \\
\hline
\end{tabular}

Spearman's rho correlation coefficients are shown for associations between $\left[{ }^{18} \mathrm{~F}\right]$ flortaucipir $\mathrm{BP} \mathrm{ND}_{\mathrm{ND}}$ (partial volume corrected) or $\left[{ }^{11} \mathrm{C}\right] \mathrm{UCB}-\mathrm{J} B \mathrm{BP}_{\mathrm{ND}}$ with MEG spectral measures (relative delta, theta and alpha power, absolute broadband power and peak frequency). Associations that remained significant upon correcting for multiple ROIs per subject using GEE analyses are highlighted in colour (green: positive association; red: negative association)

${ }^{*} p<0.05 ;{ }^{* *} p<0.01$

0.001) (Table 1 and Fig. 3a, with $\mathrm{AD}$ subject numbers analogous to Fig. 1), most markedly across regions in the occipital lobe. Across regions in the frontal lobe, an opposite association with relative delta power was observed $(r=-0.36, p=0.005)$. Furthermore, higher $\left[{ }^{18} \mathrm{~F}\right]$ flortaucipir $\mathrm{BP}_{\mathrm{ND}}$ was associated with lower broadband power across all brain lobes (occipital: $r=-0.74, p<0.001$; temporal: $r=-0.51, p=0.001$; parietal: $r=-0.54, p=$ 0.006 ; frontal: $r=-0.50, p<0.001)$. No associations were observed with peak frequency. Scatterplots for the associations in the temporal, parietal and frontal lobe are shown in Supplementary Figure 1-3. After correcting for dependency of ROIs within subjects using GEE analyses, the associations with relative delta power in the occipital and frontal lobe, relative alpha power in the occipital lobe, and all associations with broadband power remained significant (highlighted in colour in Table 1; for GEE beta's and $p$-values, see Table 2).

Third, we examined the association between synaptic density and synaptic function. Higher regional $\left[{ }^{11} \mathrm{C}\right] \mathrm{UCB}-\mathrm{J}$ $\mathrm{BP}_{\mathrm{ND}}$ was associated with higher relative alpha (occipital: $r=0.52, p=0.010$ ), higher relative theta power (occipital; $r=0.73, p<0.001$; parietal: $r=0.52 ; p=0.005)$ and lower relative delta power (occipital: $r=-0.54 ; p=0.007$ ) (Table 1 and Fig. 3b). Again, across regions in the frontal lobe, an opposite association was observed with relative delta power $(r=0.44, \quad p<0.001)$. Finally, higher regional $\left[{ }^{11} \mathrm{C}\right] \mathrm{UCB}-\mathrm{J} \mathrm{BP}_{\mathrm{ND}}$ was associated with higher broadband power in the occipital lobe $(r=0.50, p=0.013)$. Again, no associations were observed with peak frequency. Scatterplots for the associations in the temporal, parietal and frontal lobe are shown in Supplementary Figure 1-3. After correcting for dependency of ROIs within subjects using GEE analyses, the associations with occipital relative delta, theta and alpha power, and frontal delta power, remained significant, while occipital broadband power and parietal relative theta power lost significance (highlighted in colour in Table 1; for GEE beta's and $p$-values, see Table 2).

\section{Exploratory analyses}

Finally, we explored the association between each imaging modality and cognition. MMSE was strongly associated with $\left[{ }^{18} \mathrm{~F}\right]$ flortaucipir $\mathrm{BP}_{\mathrm{ND}}(r=-0.97 ; p<$ 0.001). MMSE was not associated with $\left[{ }^{11} \mathrm{C}\right] \mathrm{UCB}-\mathrm{J}$ $\mathrm{BP}_{\mathrm{ND}} \quad(r=0.39 ; p=0.39)$, MEG occipital absolute broadband power $(r=0.79, p=0.06)$, or occipital alpha power $\quad(r=0.71 ; \quad p=0.12) \quad$ (Supplementary Figure 4). 


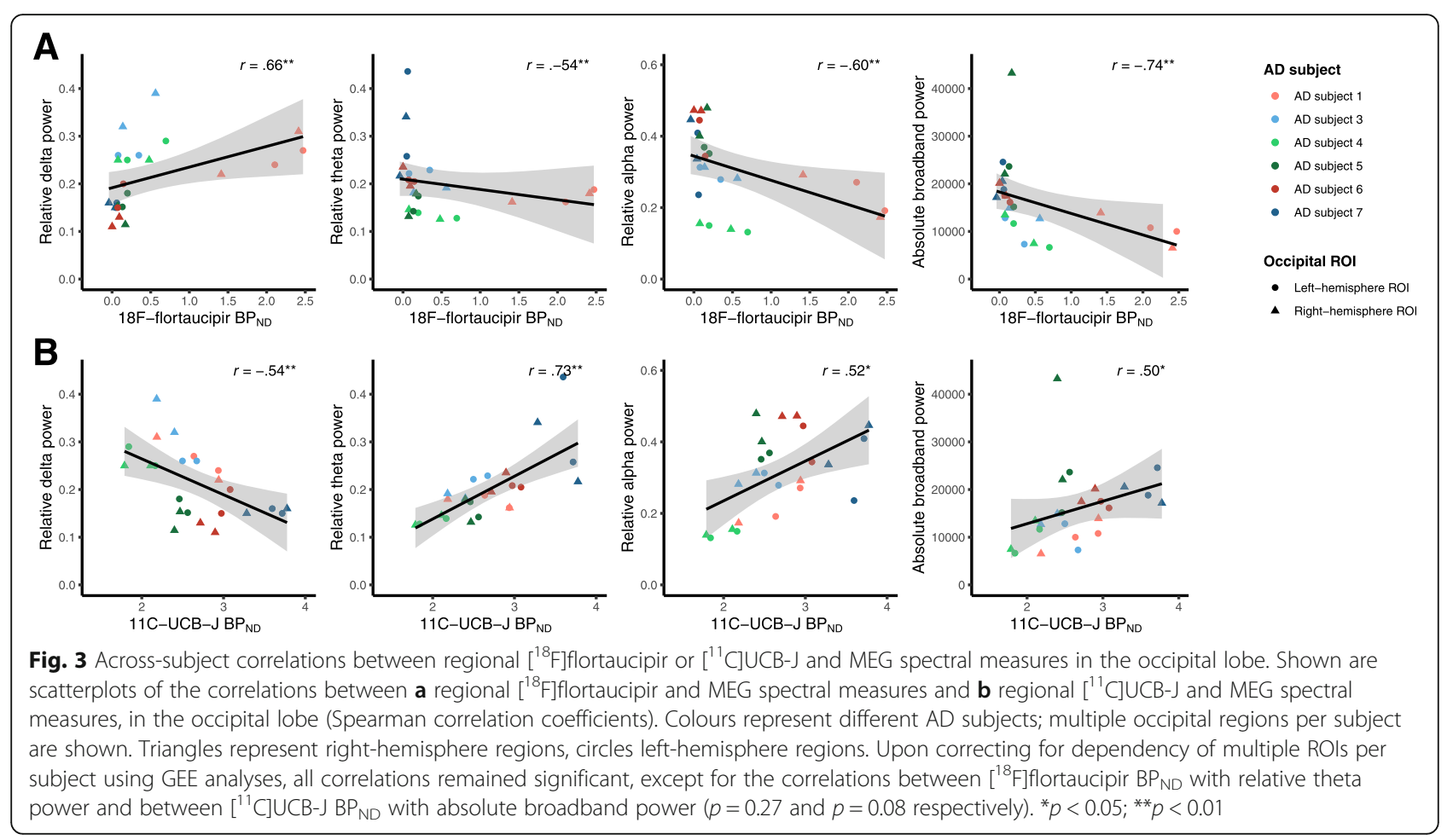

\section{Discussion}

In the present study, we examined the in vivo associations between tau pathology, synaptic density and synaptic function in AD. In line with our hypotheses, higher $\left[{ }^{18} \mathrm{~F}\right]$ flortaucipir uptake was associated with lower $\left[{ }^{11} \mathrm{C}\right]$ UCB-J uptake across subjects. Moreover, both higher $\left[{ }^{18} \mathrm{~F}\right]$ flortaucipir and lower $\left[{ }^{11} \mathrm{C}\right] \mathrm{UCB}-\mathrm{J}$ uptake were associated with altered synaptic function in the occipital lobe. Furthermore, higher $\left[{ }^{18} \mathrm{~F}\right]$ flortaucipir binding was associated to loss of absolute broadband power across all brain lobes. Finally, we observed that within-subject regional associations between $\left[{ }^{18} \mathrm{~F}\right]$ flortaucipir and $\left[{ }^{11} \mathrm{C}\right]$ UCB-J uptake depended on the degree of neocortical tau pathology. Our results provide in vivo support for an interaction between tau pathology and the synapse.

Across subjects, regional higher tau pathology was associated with synaptic loss. This negative association across regions was particularly strong for subjects with substantial neocortical tau burden. This is in line with post-mortem human brain studies that showed lower levels of synaptic protein expression in NFT-containing neurons compared to neurons without NFT $[11,12,50]$. We furthermore observed a high level of spatial overlap between higher $\left[{ }^{18} \mathrm{~F}\right]$ flortaucipir and lower $\left[{ }^{11} \mathrm{C}\right] \mathrm{UCB}-\mathrm{J}$ binding (Fig. 1). In line with a previous study from Vanhaute and others [21], the pattern of tau pathology was slightly more widespread and pronounced compared to the pattern of reduced synaptic density, which corresponds with a conceptual model that suggests tau to precede and potentially drive structural degeneration and loss of synaptic function [51].

In our study, we provide in vivo evidence for an association between tau pathology and altered synaptic function. Higher $\left[{ }^{18} \mathrm{~F}\right]$ flortaucipir uptake was associated with higher relative oscillatory power in lower frequencies (delta) and lower relative power in higher frequencies (alpha). These findings are suggestive of oscillatory slowing, which is typically characterized by higher relative power in the delta and theta frequency bands, lower relative power in the alpha and beta bands and lower peak frequency. However, we did not find associations with peak frequency, possibly due to the small sample size. In addition, a negative association with relative theta power was observed, although it did not survive correction for dependency of ROIs within subjects. Our findings were most pronounced in the occipital lobe, where the posterior dominant rhythm during a resting state eyes closed condition normally is present. This is in agreement with previous quantitative MEG/EEG studies reporting slowing of oscillatory activity most frequently in parietal, occipital and temporal areas in $\mathrm{AD}$ $[27,52]$, and has previously been linked to synaptic dysfunction [53]. Indeed, dysfunction in both excitatory or inhibitory synaptic transmission has been proposed as root causes for the altered brain function in $\mathrm{AD}[54,55]$.

In the present study, we used absolute broadband power as a reflection of overall neuronal activity $[26,56]$, which 
Table 2 Across-subject generalized estimating equations between regional $\left[{ }^{18} \mathrm{~F}\right]$ flortaucipir $\mathrm{BP}_{\mathrm{ND}}$ or $\left[{ }^{11} \mathrm{C}\right] \mathrm{UCB}-\mathrm{J}$ BP $\mathrm{ND}$ and MEG spectral measurements

\begin{tabular}{|c|c|c|c|c|}
\hline & \multicolumn{4}{|c|}{$\left[{ }^{18}\right.$ F]flortaucipir BP ${ }_{\mathrm{ND}}$ vs. MEG spectral measures } \\
\hline & Occipital & Temporal & Parietal & Frontal \\
\hline Relative delta power $(0.5-4 \mathrm{~Hz})$ & $\begin{array}{l}\beta=0.41 \\
p<0.001\end{array}$ & n.a. & n.a. & $\begin{array}{l}\beta=-0.50 \\
p<0.001\end{array}$ \\
\hline Relative theta power $(4-8 \mathrm{~Hz})$ & $\begin{array}{l}\beta=-0.08 \\
p=0.27\end{array}$ & n.a. & n.a. & n.a. \\
\hline Relative alpha power $(8-13 \mathrm{~Hz})$ & $\begin{array}{l}\beta=-0.54 \\
p<0.001\end{array}$ & n.a. & $\begin{array}{l}\beta=-0.37 \\
p=0.10\end{array}$ & n.a. \\
\hline Absolute broadband power $(0.5-48 \mathrm{~Hz})$ & $\begin{array}{l}\beta=-0.36 \\
p<0.001\end{array}$ & $\begin{array}{l}\beta=-0.34 \\
p=0.04\end{array}$ & $\begin{array}{l}\beta=-0.43 \\
p<0.001\end{array}$ & $\begin{array}{l}\beta=-0.47 \\
p<0.001\end{array}$ \\
\hline \multirow[t]{3}{*}{ Peak frequency } & n.a. & n.a. & n.a. & n.a. \\
\hline & \multicolumn{4}{|c|}{$\left[{ }^{11} \mathrm{C}\right] \mathrm{UCB}-J \mathrm{BP}_{\mathrm{ND}}$ vs. MEG spectral measures } \\
\hline & Occipital & Temporal & Parietal & Frontal \\
\hline Relative delta power $(0.5-4 \mathrm{~Hz})$ & $\begin{array}{l}\beta=-0.48 \\
p=0.01\end{array}$ & n.a. & n.a. & $\begin{array}{l}\beta=0.51 \\
p<0.001\end{array}$ \\
\hline Relative theta power $(4-8 \mathrm{~Hz})$ & $\begin{array}{l}\beta=0.68 \\
p<0.001\end{array}$ & n.a. & $\begin{array}{l}\beta=0.44 \\
p=0.06\end{array}$ & n.a. \\
\hline Relative alpha power $(8-13 \mathrm{~Hz})$ & $\begin{array}{l}\beta=0.61 \\
p<0.01\end{array}$ & n.a. & n.a. & n.a. \\
\hline Absolute broadband power $(0.5-48 \mathrm{~Hz})$ & $\begin{array}{l}\beta=0.30 \\
p=0.08\end{array}$ & n.a. & n.a. & n.a. \\
\hline Peak frequency & n.a. & n.a. & n.a. & n.a. \\
\hline
\end{tabular}

We only computed generalized estimating equations (GEE) for those associations that were significant when assessed with Spearman correlations (Table 1).

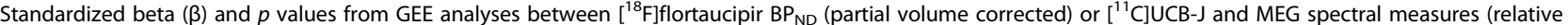
delta, theta and alpha power; absolute broadband power; and peak frequency) are shown. In green, significantly positive associations are shown; in red, significantly negative associations are shown

has been shown to decrease with increasing neurodegeneration [26]. We found that higher tau load was consistently associated with lower broadband power in all brain lobes, suggesting that with increasing tau load, total neuronal activity declines. Overall, our results suggest that higher tau pathology is correlated with alterations in synaptic activity, as expressions of synaptic degeneration or dysfunction.

We found opposite patterns between $\left[{ }^{11} \mathrm{C}\right] \mathrm{UCB}-\mathrm{J}$ uptake and MEG relative power measures as compared to $\left[{ }^{18} \mathrm{~F}\right]$ flortaucipir binding. More specifically, we observed that lower synaptic density was associated with higher relative delta power, and with lower relative theta and lower alpha power, particularly in the occipital lobe. We only found an association between higher $\left[{ }^{11} \mathrm{C}\right] \mathrm{UCB}-\mathrm{J}$ uptake and higher absolute broadband power in the occipital lobe; however, this association lost significance upon correcting for dependency of ROIs within subjects. The findings in the occipital lobe carefully suggest that regional loss of synapses is related to more oscillatory slowing and decline in neuronal activity.

Counterintuitive effects were observed in the frontal lobe for both $\left[{ }^{18} \mathrm{~F}\right]$ flortaucipir and $\left[{ }^{11} \mathrm{C}\right] \mathrm{UCB}-\mathrm{J}$ uptake in relation to relative delta power. The frontal regions in MEG are known to have low signal to noise ratio. We postulate that the counterintuitive results could have been caused by the use of relative instead of absolute values of band power, where relative delta power is artificially high (i.e. even with low broadband power, the 
sum of all relative band power values is 1 by definition). Another explanation may be the high prevalence of artefacts (e.g. due to eye movements) in the frontal regions, even after using source reconstructed data. Indeed, a previous MEG study also showed high frontal relative delta power in both AD and healthy subjects [57] without differences between groups. These associations should therefore be interpreted with caution. However, recent findings by Ranasinghe and colleagues do suggest that the frontal delta band may contain clinically relevant information regarding the role of tau pathology in Alzheimer's disease [49].

Ranasinghe and colleagues evaluated the association between $\left[{ }^{18} \mathrm{~F}\right]$ flortaucipir PET and an MEG measure of functional connectivity between neuronal populations [49]. Direct comparisons should be made with caution, as in our study we used spectral measures within neuronal populations (i.e. relative power) while Ranasinghe et al. used a measure of functional connectivity between neuronal populations (i.e. imaginary coherence). They observed that $\left[{ }^{18} \mathrm{~F}\right]$ flortaucipir uptake strongly colocalized with alpha band hypo-synchrony and deltatheta band hyper-synchrony. Spatial colocalization between $\left[{ }^{18} \mathrm{~F}\right]$ flortaucipir uptake and functional connectivity was most pronounced in temporoparietal regions, while our results were most pronounced in the occipital lobe. Additionally, Ranasinghe et al. identified the bilateral occipital regions among the key regions that show alpha hypo-synchrony in AD compared to controls. Since functional connectivity measures reflect different aspects of brain function than spectral measures, this divergence in regional specificity for correlations between $\left[{ }^{18} \mathrm{~F}\right]$ flortaucipir uptake and different aspects of neuronal functioning could be further investigated in future studies. Nevertheless, the similarities in frequency-specific MEG associations with tau pathology between this and our study are promising.

Although we performed a cross-sectional study, and causation cannot be inferred, our findings may reflect synaptic loss as a consequence of tau pathology. This is corroborated by our within-subject results which showed that the association between tau pathology and synaptic density depended on the level of neocortical tau load. More specifically, positive associations were observed when neocortical tau load was low, gradually changing into negative associations with increasing neocortical tau burden. The AD subjects showing positive associations scored relatively high on the MMSE and had a relatively high age compared to the other AD subjects (see Fig. 1), though further research is needed to look into this pattern in more detail. Importantly, all AD subjects in the current study showed evidence for the presence of $A \beta$ pathology. The positive within-subject association between tau pathology and synaptic density in low-tau subjects could be driven by the presence of $A \beta$ pathology without substantial tau pathology, while the negative within-subject association in high-tau subjects could be driven by tau pathology. It has also previously been reported that differential phases in functional connectivity may be present in relation to $\mathrm{AD}$ pathology, with a phase of hyper-connectivity in $A \beta$-positive individuals when neocortical tau was low, and a phase of hypoconnectivity when neocortical tau was high [58]. In line with these findings, our results may also indicate a phase of regional synaptic upregulation in the presence of predominantly $\mathrm{A} \beta$ pathology, gradually resulting in a phase of regional synaptic loss with additional increased neocortical tau pathology, suggesting $A \beta$ and tau to act in concert in synaptic degeneration.

Increasing evidence suggests that the spreading of tau pathology in AD may occur trans-synaptically [59], making synapses a particularly vulnerable site for tau-related structural damage. In previous in vitro and $A D$ mouse model studies, enhancement of synaptic activity has been reported to stimulate the release and spread of endogenous tau and to accelerate tauopathy [60-62]. Other studies showed that pathological tau in turn reduced the activity of functionally connected neurons as measured with intracellular recordings, and perturbed the synchronous synaptic activity pattern of the network $[63,64]$. In line with current hypotheses from different in vivo imaging modalities $[26,58,65,66], \mathrm{A} \beta$ deposition in the early phases of AD may initially cause a phase of hyperactivity, which could in turn enhance or stimulate regional tau deposition. In later phases of $\mathrm{AD}$, this process may lead to more widespread tau deposition, neuronal damage and synaptic loss and eventually cognitive decline. Our within-subject differential associations between tau pathology and synaptic density may add support to these hypotheses. However, although we observed an association between tau pathology and MMSE, MMSE was not associated with synaptic density in our sample. This may be related to our small sample size, and future studies with larger sample sizes are needed to investigate this further.

\section{Limitations}

This proof-of-concept study has a few limitations, with the main limitation being the sample size. Therefore, cautious interpretation of our findings is needed. It must be noted that the dynamic range and extent of synaptic loss needed for $\left[{ }^{11} \mathrm{C}\right]$ UCB-J PET detection is currently unknown. Furthermore, no partial volume correction was applied to the $\left[{ }^{11} \mathrm{C}\right] \mathrm{UCB}-\mathrm{J}$ data because this has not yet been validated. Importantly, it must be taken into account that the $\left[{ }^{18} \mathrm{~F}\right]$ flortaucipir tracer provides a measure for NFT pathology, while most preclinical studies have shown oligomeric tau as the pathological tau isoform at 
the synapse. In addition, there was a time window of 69 month times between PET and MEG measurements. Another limitation to be considered is the use of anticholinergic medication of subjects $1,3,4$ and 7 , which is a known modulator of oscillatory activity. However, previous research suggests that administration of cholinesterase inhibitors reverses the slowing of oscillatory activity, i.e. delta and theta rhythms decrease and alpha rhythms increase $[67,68]$. All subjects with high tau burden who underwent MEG measurement used anticholinergic medication; therefore, the effects found in this study may have been an underestimation of the true effects. Additionally, because of the small sample size, it was not possible to remove subjects with suboptimal epochs (e.g. those that included possible effects of drowsiness) from the analysis. Recent work suggest though that this may have minimal effect on the spectral measures used in the current study [69]. Also, the postulated loss of absolute broadband power as a measure of neurodegeneration needs to be further confirmed with other methods that reflect overall activity. Notwithstanding, despite a small sample size, we found relatively strong and robust findings between tau pathology, synaptic loss and synaptic (dys)function. We used state-of-the art quantification methods, and our results may contribute to a better understanding of the third AD pathological hallmark-synaptic loss-and may generate new hypotheses about synaptic plasticity in relation to $A D$ pathology.

\section{Conclusions}

Overall, we provide preliminary in vivo evidence for the spatial and frequency-specific association between tau pathology, synaptic loss and synaptic dysfunction. Within-subject associations between tau pathology and synaptic density may depend on the total neocortical tau burden. These results indicate that in Alzheimer's disease tau pathology is closely associated with affected synaptic density and synaptic function.

\section{Supplementary Information}

The online version contains supplementary material available at https://doi. org/10.1186/s13195-021-00772-0.

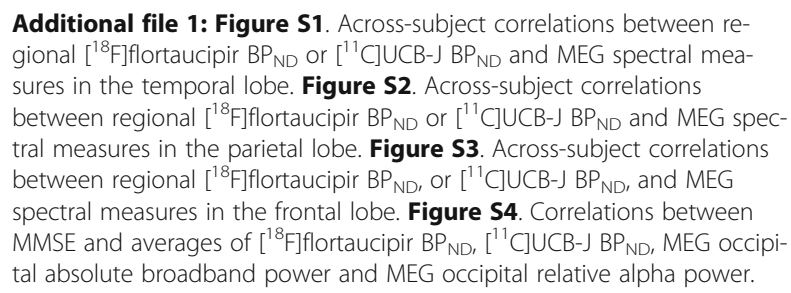

\section{Abbreviations}

Aß: Amyloid- B; NFT: Neurofibrillary tangles; AD: Alzheimer's disease

PET: Positron emission tomography; SV2A: Synaptic vesicle glycoprotein 2A;
MEG: Magnetoencephalography; CSF: Cerebrospinal fluid; MMSE: Mini-Mental State Examination; MRI: Magnetic resonance imaging; ROI: Region of interest; $V_{\mathrm{T}}$ : Volumes of distribution; $\mathrm{BP}_{\mathrm{ND}}$ : Binding potential; DVR: Distribution volume ratio; RPM: Receptor parametric mapping; GEE: Generalized estimating equation

\section{Acknowledgements}

The authors kindly thank all participants for their contribution. We thank R. Babapour and J. Ebenau for their contributions in the acquisition of the PET data. The authors thank technicians C.H. Plugge, N.C. Akemann, N.

Zwagerman and M.C. Alting Siberg for acquisition of the MEG data.

\section{Authors' contributions}

E.C., D.S., S.V., A.H., A.G. and B.B. contributed to study concept and design. E.C., D.S., H.T., E.W., R.B., P.S., R.S., A.W., F.B., S.G. and A.H. contributed to data acquisition and analysis. E.C., D.S., S.V., R.O., A.B., W.S., S.S., J.M.R., Ph.S., A.H., A.G. and B. B contributed to drafting the text and figures. All authors critically evaluated and approved the manuscript.

\section{Funding}

This study was made possible by ZonMW Memorabel and ZonMW Top grants. In addition, $\left[{ }^{11} \mathrm{C}\right]$ UCB-J PET scans were made possible by Rodin Therapeutics Inc.; $\left[{ }^{18} \mathrm{~F}\right.$ f flortaucipir PET scans were made possible by Avid Radiopharmaceuticals Inc. Research of Amsterdam Alzheimer Center is part of the Neurodegeneration programme of Amsterdam Neuroscience. The Amsterdam Alzheimer Center is supported by Alzheimer Nederland and Stichting VUmc funds.

\section{Availability of data and materials}

The data used in this study are not publicly available, but may be provided upon reasonable request.

\section{Ethics approval and consent to participate}

The BEBO Foundation Medical Ethics Committee (Assen, The Netherlands) and the local Institutional Review Board of the VUmc (Amsterdam, The Netherlands) approved the study. All subjects provided written informed consent prior to the study.

\section{Consent for publication}

Not applicable.

\section{Competing interests}

E.C., D.S., H.T., S.V., E.W., R.B., R.O., A.B., W.S., P.S., R.S., A.W., F.B., Ph.S., S.G., A.H., A.G. and B.B. declare that they have no conflict of interest.

S.S. and J.M.R. are employees of Rodin Therapeutics Inc.; they contributed to the implementation and writing of this study, but did not contribute to the design and analysis of this report.

\section{Author details}

${ }^{1}$ Department of Radiology \& Nuclear Medicine, Amsterdam Neuroscience, Vrije Universiteit Amsterdam, Amsterdam UMC, Amsterdam, The Netherlands. ${ }^{2}$ Alzheimer Center Amsterdam, Department of Neurology, Amsterdam Neuroscience, Vrije Universiteit Amsterdam, Amsterdam UMC, Amsterdam, The Netherlands. ${ }^{3}$ Department of Clinical Neurophysiology and MEG Center, Department of Neurology, Amsterdam Neuroscience, Vrije Universiteit Amsterdam, Amsterdam UMC, Amsterdam, The Netherlands. ${ }^{4}$ Clinical Memory Research Unit, Lund University, Lund, Sweden. ${ }^{5}$ Department of Clinical Genetics, Amsterdam Neuroscience, Amsterdam UMC, Amsterdam, The Netherlands. ${ }^{6}$ Center for Neurogenomics and Cognitive Research, Department of Functional Genomics, Faculty of Science, Vrije Universiteit, Amsterdam, The Netherlands. ${ }^{7}$ Department of Anaesthesiology, Vrije Universiteit Amsterdam, Amsterdam UMC, Amsterdam, The Netherlands. ${ }^{8}$ Rodin Therapeutics Inc., Cambridge, MA, USA. ${ }^{9}$ UCL Institutes of Neurology and Healthcare Engineering, London, UK.

Received: 3 August 2020 Accepted: 11 January 2021 Published online: 05 February 2021

\section{References}

1. Scheltens P, Blennow K, Breteler MM, de Strooper B, Frisoni GB, Salloway S, et al. Alzheimer's disease. Lancet. 2016;388(10043):505-17. 
2. DeKosky ST, Scheff SW. Synapse loss in frontal cortex biopsies in Alzheimer's disease: correlation with cognitive severity. Ann Neurol. 1990;27(5):457-64.

3. Terry RD, Masliah E, Salmon DP, Butters N, DeTeresa R, Hill R, et al. Physical basis of cognitive alterations in Alzheimer's disease: synapse loss is the major correlate of cognitive impairment. Ann Neurol. 1991;30(4):572-80.

4. Bejanin A, Schonhaut DR, La Joie R, Kramer JH, Baker SL, Sosa N, et al. Tau pathology and neurodegeneration contribute to cognitive impairment in Alzheimer's disease. Brain. 2017;140(12):3286-300.

5. Ossenkoppele R, Schonhaut DR, Scholl M, Lockhart SN, Ayakta N, Baker SL, et al. Tau PET patterns mirror clinical and neuroanatomical variability in Alzheimer's disease. Brain. 2016;139(Pt 5):1551-67.

6. Ossenkoppele R, Smith R, Ohlsson T, Strandberg O, Mattsson N, Insel PS, et al. Associations between tau, Abeta, and cortical thickness with cognition in Alzheimer disease. Neurology. 2019;92(6):e601-e12.

7. Scholl M, Lockhart SN, Schonhaut DR, O'Neil JP, Janabi M, Ossenkoppele R, et al. PET imaging of tau deposition in the aging human brain. Neuron. 2016:89(5):971-82

8. Fein JA, Sokolow S, Miller CA, Vinters HV, Yang F, Cole GM, et al. Colocalization of amyloid beta and tau pathology in Alzheimer's disease synaptosomes. Am J Pathol. 2008;172(6):1683-92.

9. Henkins KM, Sokolow S, Miller CA, Vinters HV, Poon WW, Cornwell LB, et al. Extensive p-tau pathology and SDS-stable p-tau oligomers in Alzheimer's cortical synapses. Brain Pathol. 2012;22(6):826-33.

10. Sokolow S, Henkins KM, Bilousova T, Gonzalez B, Vinters HV, Miller CA, et al. Pre-synaptic C-terminal truncated tau is released from cortical synapses in Alzheimer's disease. J Neurochem. 2015;133(3):368-79.

11. Callahan LM, Vaules WA, Coleman PD. Quantitative decrease in synaptophysin message expression and increase in cathepsin D message expression in Alzheimer disease neurons containing neurofibrillary tangles. Neuropathol Exp Neurol. 1999;58(3):275-87.

12. Spires-Jones TL, Hyman BT. The intersection of amyloid beta and tau at synapses in Alzheimer's disease. Neuron. 2014;82(4):756-71.

13. Lasagna-Reeves CA, Castillo-Carranza DL, Sengupta U, Clos AL, Jackson GR, Kayed R. Tau oligomers impair memory and induce synaptic and mitochondrial dysfunction in wild-type mice. Mol Neurodegener. 2011;6:39.

14. Zhou L, McInnes J, Wierda K, Holt M, Herrmann AG, Jackson RJ, et al. Tau association with synaptic vesicles causes presynaptic dysfunction. Nat Commun. 2017:8:15295.

15. Finnema SJ, Nabulsi NB, Eid T, Detyniecki K, Lin SF, Chen MK, et al. Imaging synaptic density in the living human brain. Sci Transl Med. 2016;8(348): 348 ra96.

16. Heurling K, Ashton NJ, Leuzy A, Zimmer ER, Blennow K, Zetterberg $\mathrm{H}$, et al. Synaptic vesicle protein $2 \mathrm{~A}$ as a potential biomarker in synaptopathies. Mol Cell Neurosci. 2019;97:34-42.

17. Chen MK, Mecca AP, Naganawa M, Finnema SJ, Toyonaga T, Lin SF, et al. Assessing synaptic density in Alzheimer disease with synaptic vesicle glycoprotein 2A positron emission tomographic imaging. JAMA Neurol. 2018;75(10):1215-24

18. Bastin C, Bahri MA, Meyer F, Manard M, Delhaye E, Plenevaux A, et al. In vivo imaging of synaptic loss in Alzheimer's disease with [18F]UCB-H positron emission tomography. Eur J Nucl Med Mol Imaging. 2020;47:390-402.

19. Mecca AP, Chen MK, O'Dell RS, Naganawa M, Toyonaga T, Godek TA, et al. In vivo measurement of widespread synaptic loss in Alzheimer's disease with SV2A PET. Alzheimers Dement. 2020;16(7):974-82.

20. Scheltens P, Leys D, Barkhof F, Huglo D, Weinstein HC, Vermersch P, et al. Atrophy of medial temporal lobes on MRI in "probable" Alzheimer's disease and normal ageing: diagnostic value and neuropsychological correlates. J Neurol Neurosurg Psychiatry. 1992;55(10):967-72.

21. Vanhaute $H$, Ceccarini J, Michiels L, Koole M, Sunaert S, Lemmens R, et al. In vivo synaptic density loss is related to tau deposition in amnestic mild cognitive impairment. Neurology. 2020;95:e545-e553.

22. da Silva FL. EEG and MEG: relevance to neuroscience. Neuron. 2013;80(5): $1112-28$.

23. Hari R, Baillet S, Barnes G, Burgess R, Forss N, Gross J, et al. IFCN-endorsed practical guidelines for clinical magnetoencephalography (MEG). Clin Neurophysiol. 2018;129(8):1720-47.

24. Gao R, Peterson EJ, Voytek B. Inferring synaptic excitation/inhibition balance from field potentials. Neuroimage. 2017;158:70-8.

25. Atallah BV, Scanziani M. Instantaneous modulation of gamma oscillation frequency by balancing excitation with inhibition. Neuron. 2009;62(4): 566-77.
26. de Haan W, Mott K, van Straaten EC, Scheltens P, Stam CJ. Activity dependent degeneration explains hub vulnerability in Alzheimer's disease. Plos Comput Biol. 2012;8(8):e1002582

27. Engels MMA, van der Flier WM, Stam CJ, Hillebrand A, Scheltens P, van Straaten ECW. Alzheimer's disease: the state of the art in resting-state magnetoencephalography. Clin Neurophysiol. 2017;128(8):1426-37.

28. McKhann GM, Knopman DS, Chertkow H, Hyman BT, Jack CR Jr, Kawas CH, et al. The diagnosis of dementia due to Alzheimer's disease: recommendations from the National Institute on Aging-Alzheimer's Association workgroups on diagnostic guidelines for Alzheimer's disease. Alzheimers Dement. 2011;7(3):263-9.

29. van der Flier WM, Scheltens P. Amsterdam dementia cohort: performing research to optimize care. J Alzheimers Dis. 2018:62(3):1091-111.

30. Tuncel H, Boellaard R, Coomans EM, de Vries EF, Glaudemans AW, Feltes PK, et al. Kinetics and 28-day test-retest repeatability and reproducibility of [11C]UCB-J PET brain imaging. J Cereb Blood Flow Metab. 2020;0(0): $0271678 \times 20964248$

31. Golla SSV, Timmers T, Ossenkoppele R, Groot C, Verfaillie S, Scheltens P, et al. Quantification of tau load using [(18) F]AV1451 PET. Mol Imaging Biol. 2017;19(6):963-71

32. Hammers A, Allom R, Koepp MJ, Free SL, Myers R, Lemieux L, et al. Threedimensional maximum probability atlas of the human brain, with particular reference to the temporal lobe. Hum Brain Mapp. 2003;19(4):224-47.

33. Svarer C, Madsen K, Hasselbalch SG, Pinborg LH, Haugbol S, Frokjaer VG, et al. MR-based automatic delineation of volumes of interest in human brain PET images using probability maps. Neuroimage. 2005;24(4):969-79.

34. Koole M, van Aalst J, Devrome M, Mertens N, Serdons K, Lacroix B, et al. Quantifying SV2A density and drug occupancy in the human brain using [(11) C]UCB-J PET imaging and subcortical white matter as reference tissue. Eur J Nucl Med Mol Imaging. 2019:46(2):396-406.

35. Finnema SJ, Nabulsi NB, Mercier J, Lin SF, Chen MK, Matuskey D, et al. Kinetic evaluation and test-retest reproducibility of [(11) C]UCB-J, a novel radioligand for positron emission tomography imaging of synaptic vesicle glycoprotein 2A in humans. J Cereb Blood Flow Metab. 2018;38(11):2041-52.

36. Golla SS, Wolters EE, Timmers T, Ossenkoppele R, van der Weijden CW, Scheltens P, et al. Parametric methods for [(18) F] flortaucipir PET. J Cereb Blood Flow Metab. 2018;40:271678X18820765.

37. Golla SSV, Lubberink M, van Berckel BNM, Lammertsma AA, Boellaard R. Partial volume correction of brain PET studies using iterative deconvolution in combination with HYPR denoising. EJNMMI Res. 2017;7(1):36.

38. Taulu S, Simola J. Spatiotemporal signal space separation method for rejecting nearby interference in MEG measurements. Phys Med Biol. 2006;51(7):1759-68.

39. Hillebrand A, Fazio P, de Munck JC, van Dijk BW. Feasibility of clinical magnetoencephalography (MEG) functional mapping in the presence of dental artefacts. Clin Neurophysiol. 2013;124(1):107-13.

40. Hillebrand A, Barnes GR, Bosboom JL, Berendse HW, Stam CJ. Frequencydependent functional connectivity within resting-state networks: an atlasbased MEG beamformer solution. Neuroimage. 2012;59(4):3909-21.

41. Hillebrand A, Tewarie P, van Dellen E, Yu M, Carbo EW, Douw L, et al. Direction of information flow in large-scale resting-state networks is frequency-dependent. Proc Natl Acad Sci U S A. 2016;113(14):3867-72.

42. Hillebrand A, Barnes GR. Beamformer analysis of MEG data. Int Rev Neurobiol. 2005;68:149-71.

43. Sekihara K, Nagarajan SS, Poeppel D, Marantz A. Asymptotic SNR of scalar and vector minimum-variance beamformers for neuromagnetic source reconstruction. IEEE Trans Biomed Eng. 2004;51(10):1726-34.

44. Cheyne D, Bostan AC, Gaetz W, Pang EW. Event-related beamforming: a robust method for presurgical functional mapping using MEG. Clin Neurophysiol. 2007;118(8):1691-704.

45. Ossenkoppele R, Schonhaut DR, Baker SL, O'Neil JP, Janabi M, Ghosh PM, et al. Tau, amyloid, and hypometabolism in a patient with posterior cortical atrophy. Ann Neurol. 2015;77(2):338-42.

46. Cho H, Choi JY, Hwang MS, Kim YJ, Lee HM, Lee HS, et al. In vivo cortical spreading pattern of tau and amyloid in the Alzheimer disease spectrum. Ann Neurol. 2016:80(2):247-58.

47. Gouw AA, Alsema AM, Tijms BM, Borta A, Scheltens P, Stam CJ, et al. EEG spectral analysis as a putative early prognostic biomarker in nondemented, amyloid positive subjects. Neurobiol Aging. 2017;57:133-42.

48. Segalowitz SJ, Santesso DL, Jetha MK. Electrophysiological changes during adolescence: a review. Brain Cogn. 2010;72(1):86-100. 
49. Ranasinghe KG, Cha J, laccarino L, Hinkley LB, Beagle AJ, Pham J, et al. Neurophysiological signatures in Alzheimer's disease are distinctly associated with TAU, amyloid-beta accumulation, and cognitive decline. Sci Transl Med. 2020;12(534):eaaz4069.

50. Ginsberg SD, Hemby SE, Lee VM, Eberwine JH, Trojanowski JQ. Expression profile of transcripts in Alzheimer's disease tangle-bearing CA1 neurons. Ann Neurol. 2000;48(1):77-87.

51. Jack CR Jr, Bennett DA, Blennow K, Carrillo MC, Dunn B, Haeberlein SB, et al. NIA-AA research framework: toward a biological definition of Alzheimer's disease. Alzheimers Dement. 2018;14(4):535-62.

52. Jeong J. EEG dynamics in patients with Alzheimer's disease. Clin Neurophysiol. 2004;115(7):1490-505.

53. Shah-Basak PP, Kielar A, Deschamps T, Verhoeff NP, Jokel R, Meltzer J. Spontaneous oscillatory markers of cognitive status in two forms of dementia. Hum Brain Mapp. 2019;40(5):1594-607.

54. Palop JJ, Chin J, Roberson ED, Wang J, Thwin MT, Bien-Ly N, et al. Aberrant excitatory neuronal activity and compensatory remodeling of inhibitory hippocampal circuits in mouse models of Alzheimer's disease. Neuron. 2007; 55(5):697-711.

55. Palop JJ, Mucke L. Synaptic depression and aberrant excitatory network activity in Alzheimer's disease: two faces of the same coin? NeuroMolecular Med. 2010;12(1):48-55.

56. Whitford TJ, Rennie CJ, Grieve SM, Clark CR, Gordon E, Williams LM. Brain maturation in adolescence: concurrent changes in neuroanatomy and neurophysiology. Hum Brain Mapp. 2007;28(3):228-37.

57. Engels MM, Hillebrand A, van der Flier WM, Stam CJ, Scheltens P, van Straaten EC. Slowing of hippocampal activity correlates with cognitive decline in early onset Alzheimer's disease. An MEG Study with Virtual Electrodes. Front Hum Neurosci. 2016;10:238.

58. Schultz AP, Chhatwal JP, Hedden T, Mormino EC, Hanseeuw BJ, Sepulcre J, et al. Phases of hyperconnectivity and hypoconnectivity in the default mode and salience networks track with amyloid and tau in clinically normal individuals. J Neurosci. 2017;37(16):4323-31.

59. Liu L, Drouet V, Wu JW, Witter MP, Small SA, Clelland C, et al. Trans-synaptic spread of tau pathology in vivo. Plos One. 2012;7(2):e31302.

60. Pooler AM, Phillips EC, Lau DH, Noble W, Hanger DP. Physiological release of endogenous tau is stimulated by neuronal activity. EMBO Rep. 2013;14(4): 389-94

61. Wu JW, Hussaini SA, Bastille IM, Rodriguez GA, Mrejeru A, Rilett K, et al. Neuronal activity enhances tau propagation and tau pathology in vivo. Nat Neurosci. 2016;19(8):1085-92.

62. Yamada K, Holth JK, Liao F, Stewart FR, Mahan TE, Jiang H, et al. Neuronal activity regulates extracellular tau in vivo. J Exp Med. 2014;211(3):387-93.

63. Menkes-Caspi N, Yamin HG, Kellner V, Spires-Jones TL, Cohen D, Stern EA. Pathological tau disrupts ongoing network activity. Neuron. 2015;85(5): 959-66.

64. Stancu IC, Vasconcelos B, Ris L, Wang P, Villers A, Peeraer E, et al. Templated misfolding of tau by prion-like seeding along neuronal connections impairs neuronal network function and associated behavioral outcomes in Tau transgenic mice. Acta Neuropathol. 2015;129(6):875-94.

65. Huijbers W, Schultz AP, Papp KV, LaPoint MR, Hanseeuw B, Chhatwal JP, et al. Tau accumulation in clinically normal older adults is associated with hippocampal hyperactivity. J Neurosci. 2019;39(3):548-56.

66. Sperling R. Potential of functional MRI as a biomarker in early Alzheimer's disease. Neurobiol Aging. 2011;32(Suppl 1):S37-43.

67. Bosboom UL, Stoffers D, Stam CJ, Berendse HW, Wolters E. Cholinergic modulation of MEG resting-state oscillatory activity in Parkinson's disease related dementia. Clin Neurophysiol. 2009;120(5):910-5.

68. Babiloni C, Del Percio C, Bordet R, Bourriez IL, Bentivoglio M, Payoux P, et al. Effects of acetylcholinesterase inhibitors and memantine on resting-state electroencephalographic rhythms in Alzheimer's disease patients. Clin Neurophysiol. 2013;124(5):837-50.

69. Marquetand J, Vannoni S, Carboni M, Li Hegner Y, Stier C, Braun C, et al. Reliability of magnetoencephalography and high-density electroencephalography resting-state functional connectivity metrics. Brain Connect. 2019:9(7):539-53.

\section{Publisher's Note}

Springer Nature remains neutral with regard to jurisdictional claims in published maps and institutional affiliations.

\section{Ready to submit your research? Choose BMC and benefit from}

- fast, convenient online submission

- thorough peer review by experienced researchers in your field

- rapid publication on acceptance

- support for research data, including large and complex data types

- gold Open Access which fosters wider collaboration and increased citations

- maximum visibility for your research: over $100 \mathrm{M}$ website views per year

At BMC, research is always in progress.

Learn more biomedcentral.com/submissions 